\title{
Optical properties of CdS sintered film
}

\author{
D PATIDAR, $R$ SHARMA, $N$ JAIN, T P SHARMA and N S SAXENA* \\ Department of Physics, University of Rajasthan, Jaipur 302 004, India
}

MS received 19 June 2004

\begin{abstract}
Chemical method has been used to prepare cadmium sulphide by using cadmium, hydrochloric acid and $\mathrm{H}_{2} \mathrm{~S}$. The reflection spectra of covered and uncovered sintered films of $\mathrm{CdS}$ have been recorded by 'Hitachi spectrophotometer' over the wavelength range $300-700 \mathrm{~nm}$. The energy band gaps of these films have been calculated from reflection spectra. It is found that the energy band gap of both films is same as $2.41 \mathrm{eV}$. It is indicated that energy band gap of these films does not change. This value of band gap is in good agreement with the value reported by other workers. The measurement of photocurrent has also been carried out using Keithley High Resistance meter/ Electrometer. This film shows the high photosensitivity and high photocurrent decay. Thus so obtained films are suitable for fabrication of photo detectors and solar cells.
\end{abstract}

Keywords. Chemical method; reflection spectra; energy band gap; photocurrent.

\section{Introduction}

The use of thin film polycrystalline semiconductors has attracted much interest in an expanding variety of applications in various electronic and optoelectronic devices. The technological interest in polycrystalline based devices is mainly caused by their very low production costs. Thin films now occupy a prominent place in basic research and solid state technology. Cadmium sulphide $(\mathrm{CdS})$ is a very useful optoelectronic (Iyechika et al 1988; Bogdanov and Lyssenko 1988), piezo-electronic (Kerk and Kelly 1964; Stefko 1991) and semiconducting material. The thin films of CdS are of considerable interest for their efficient use in the fabrication of solar cells (Chu et al 1992; Britt and Ferekids 1993).

In recent years, there has been a rapid development in the field of II-VI semiconductors for their use in solar cells. Cadmium sulphide belonging to the II-VI group is the most widely used material for CdS/CdTe and $\mathrm{CdS} / \mathrm{Cu}_{2} \mathrm{~S}$ heterojunction solar cells. It is because of the fact that $\mathrm{CdS}$ has intermediate energy band gap, reasonable conversion efficiency, stability and low cost (Lee and Im 1980; Nakayama et al 1980). A variety of deposition techniques have been used to grow CdS films of desirable optical, electrical and structural properties, a few of them being chemical deposition (Ocampo and Sebastian 1994; Sebastian and $\mathrm{Hu}$ 1994), physical vapour deposition (Bouchenaki et al 1990; Sravani et al 1992), spray pyrolysis (Cong and Chartier 1993; Gurumurugan et al 1994), electro deposition (Das

\footnotetext{
*Author for correspondence (n_s_saxena@ rediffmail.com)
}

1993; Edamura and Muto 1993) etc. Each of the above listed techniques has produced sulphur deficient films. In this connection, method of screen printing with sintering is one of the cheapest and convenient techniques for fabrication of both layer and an ohmic contact.

In this paper, chemical method has been used to prepare the sample $(\mathrm{CdS})$ by using $\mathrm{Cd}, \mathrm{HCl}$ and $\mathrm{H}_{2} \mathrm{~S}$ and preparing the screen printed sintered films of $\mathrm{CdS}$, on the glass substrate with the help of cadmium chloride and ethylene glycol. It is the cheapest method for preparation of the sample. Investigation of optical properties of semiconducting films is essential for proper application in semiconducting devices. The fundamental optical property which has been investigated here is reflectance of light at various wavelengths using the 'Hitachi spectrophotometer U-3400'. The energy band gaps of covered and uncovered sintered films of $\mathrm{CdS}$ are determined using the reflection spectra. The decay of photocurrent of sintered film of CdS has been determined using the 'Keithley High Resistance meter/Electrometer model $6517 \mathrm{~A}$ '.

\section{Experimental}

In the present work, samples were prepared by chemical method using $\mathrm{Cd}, \mathrm{HCl}$ and $\mathrm{H}_{2} \mathrm{~S}$. Cadmium metal $(1 \mathrm{~g})$ was completely dissolved in $\mathrm{HCl}(5 \mathrm{ml})$ solution. Then $\mathrm{H}_{2} \mathrm{~S}$ gas was passed through the solution. The reaction of precipitation for this process is given below

$$
\begin{aligned}
& \mathrm{Cd}+2 \mathrm{HCl} \rightarrow \mathrm{CdCl}_{2}+\mathrm{H}_{2}, \\
& \mathrm{CdCl}_{2}+\mathrm{H}_{2} \mathrm{~S} \rightarrow \underset{\text { (yellow) }}{\mathrm{CdS}+2 \mathrm{HCl}}
\end{aligned}
$$


The yellow precipitate obtained in the above process was filtered. This composite was then dried in an oven at $50^{\circ} \mathrm{C}$ for $30 \mathrm{~min}$. When the precipitate was completely dried, it was then crushed to fine powder by grinding process. Cadmium sulphide (CdS) films were prepared by the sintering technique. In appropriate amount of cadmium sulphide, cadmium chloride was added as an adhesive and ethylene glycol as the binder. The weight of $\mathrm{CdCl}_{2}$ was only $10 \%$ of the weight of CdS. CdS and $\mathrm{CdCl}_{2}$ were thoroughly mixed and then a few drops of ethylene glycol was added to form the paste. The paste thus prepared was screen printed on glass substrates which were cleaned by acetone and distilled water.

The films thus prepared were dried at $100^{\circ} \mathrm{C}$ for $2 \mathrm{~h}$ in open air. The reason for drying the sample at lower temperature was to avoid creaks in the samples. After this, one film was covered by glass substrate and other film was uncovered. Both films were then sintered at $400^{\circ} \mathrm{C}$ temperature for $10 \mathrm{~min}$ in the open air atmosphere. The melting point of $\mathrm{CdCl}_{2}$ was $568^{\circ} \mathrm{C}$. However, the evaporation of $\mathrm{CdCl}_{2}$ started at about $400^{\circ} \mathrm{C}$. Cadmium chloride was hygroscopic, so as to obtain stable sintered films, organic material and cadmium chloride should not remain in the sample. As the removal of organic substance takes place at about $400^{\circ} \mathrm{C}$, the sintering temperature cannot be less than $400^{\circ} \mathrm{C}$.

Reflection spectra of covered and uncovered sintered films of chemically prepared cadmium sulphide were taken at room temperature with the help of 'Hitachi spectrophotometer model U-3400' and shown in figure 1 in the wavelength region from 300-700 $\mathrm{nm}$. The energy band gaps of these films are determined from reflection spectra. Almost all the II-VI compounds are direct band gap semiconductors. According to Tauc relation, the absorption coefficient for direct band gap material is given by (Tauc 1974; Sharma et al 1992)

$$
\alpha h v=A\left(h v-E_{\mathrm{g}}\right)^{1 / 2},
$$

where $\alpha h v$ is the photon energy, $E_{\mathrm{g}}$ the band gap and $A$ a constant which is different for different transitions. The absorption coefficient, $\alpha$, may be written in terms of reflectance as

$$
2 \alpha t=\ln \left[\left(R_{\max }-R_{\min }\right) /\left(R-R_{\min }\right)\right],
$$

where $t$ is the thickness of the sample and $R$ the reflectance for any intermediate photon energy. The reflectance falls from $R_{\max }$ to $R_{\min }$ due to the absorption of light by the material.

The photocurrent characteristics of covered sintered film of chemically prepared CdS have been studied with the help of 'Keithley High Resistance meter/Electrometer model 6517 A'. By using this system, only film is illuminated for a certain interval of time in the dark atmosphere. Once the current is stabilized, the illumination is cut off after this particular interval of time. Dark current, photocurrent and photocurrent decay are recorded manually.

\section{Results and discussion}

The sintered films of chemically prepared cadmium sulphide have been prepared on the glass substrate. Reflection spectra of covered and uncovered sintered films of chemically prepared CdS were taken by 'Hitachi spectrophotometer model U-3400' at room temperature. The energy band gaps of these films have been calculated with the help of reflection spectra. We plot a graph between $(\alpha h v)^{2}$ (as ordinate) vs $h v$ (as abscissa), a straight line is obtained. The extrapolation of straight line to $(\alpha h v)^{2}=0$ axis gives the value of the energy band gap of film materials.

Figure 1 represents the reflection spectra of covered and uncovered sintered films of chemically prepared $\mathrm{CdS}$. In figures 2 and 3, a graph is plotted between $(\alpha h v)^{2}$ and $h v$, for determination of the energy band gap. The energy band gap of these films comes out to be $2.41 \mathrm{eV}$, same for both films. This value of energy band gap is in good agreement with the value reported in the literature (Kumar et al 1999). It is indicated that the energy band gap of CdS film does not change with covered film by glass substrate and uncovered film. Chemical method, one of the cheapest and convenient techniques, is used for preparing $\mathrm{CdS}$ sample.

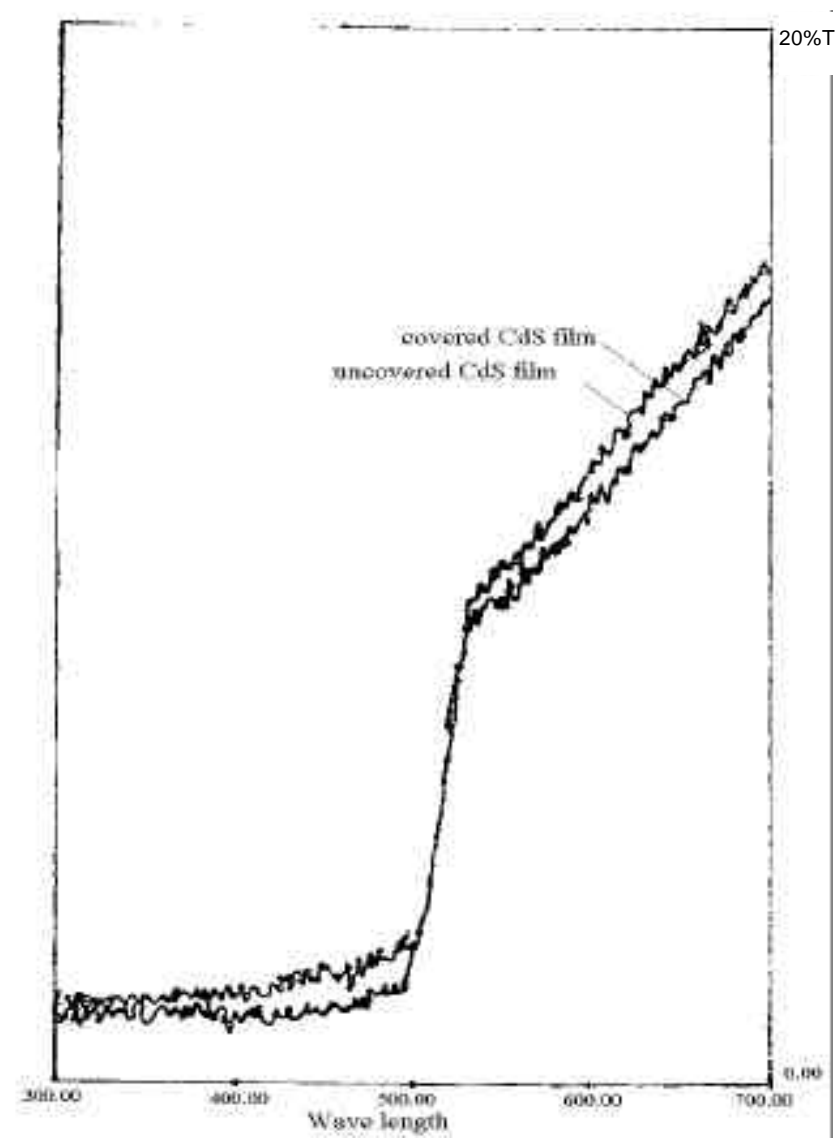

Figure 1. Reflection spectra of covered and uncovered CdS films. 


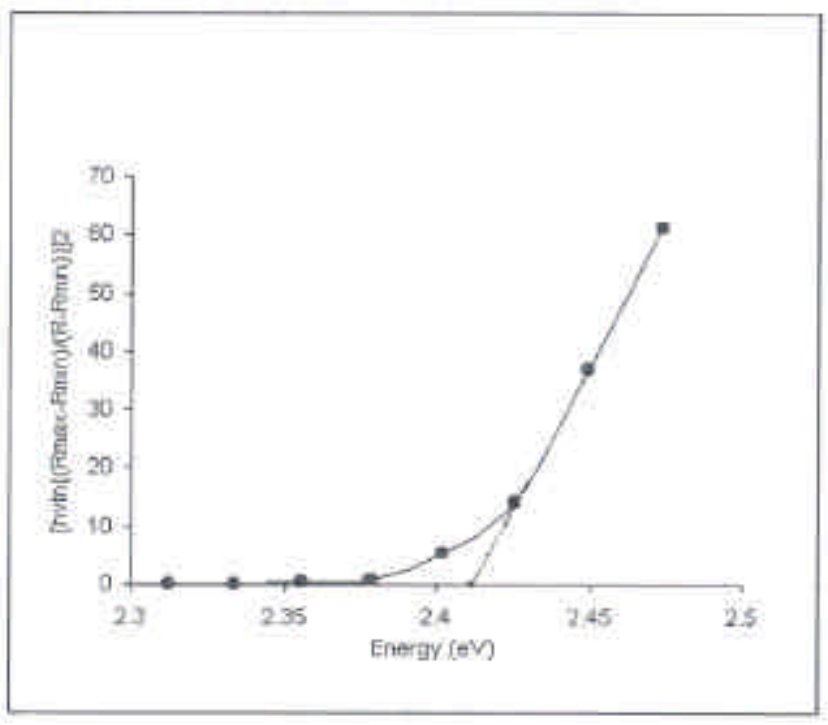

Figure 2. Energy band gap determination of covered CdS film.

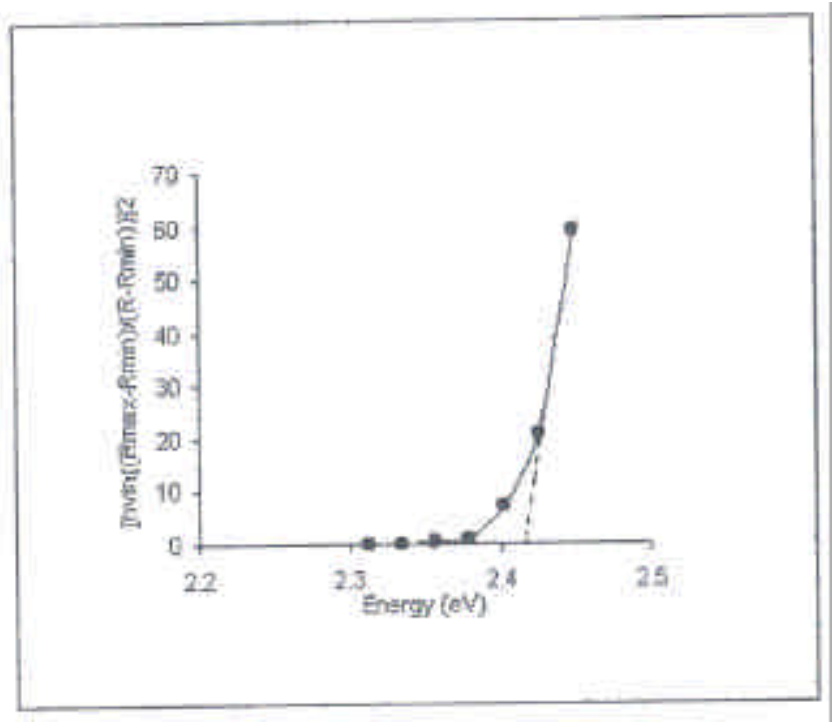

Figure 3. Energy band gap determination of uncovered $\mathrm{CdS}$ film.

\subsection{Photocurrent characteristics}

The dark current and photocurrent characteristics of covered sintered film of chemically prepared CdS are determined. This measurement has been carried out using ohmic contacts on the top layer of the film. The distance between contacts is $2 \mathrm{~mm}$ and bias voltage, $10 \mathrm{~V}$. The illumination level is $200 \mathrm{~W}$ for this measurement. The light falls on the film, the photocurrent is high and decreases with respect to time. After some time, when saturation is reached, the light is then turned off and the decay in photocurrent with time is recorded using 'Keithley High Resistance meter/Electrometer model 6517 A'. The photocurrent is obtained after subtracting the dark current from the current measured in the presence of light.

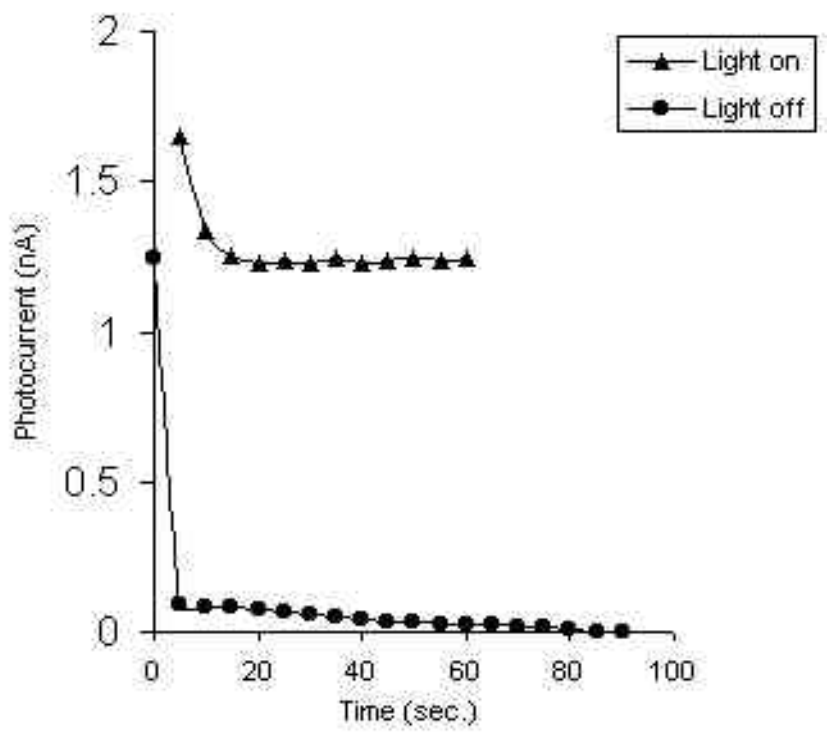

Figure 4. Variation of photocurrent with time.

Figure 4 shows the decay of photocurrent with time at room temperature for covered sintered film of chemically prepared CdS. When light is illuminated on the film, the photocurrent is high. Initially high value of the photocurrent is due to the absorption of photon by the film, which excites the electrons from the valence band to conduction band. This creates pairs of free holes in valence band and free electrons in conduction band. Most of the electrons are from the surface of the CdS film which moves from valence band to the conduction band, it increases the process of pair generation initially, which in turn increases the carrier concentration, resulting in high photocurrent. The photocurrent decreases with time and after some time, the photocurrent is almost constant. This is due to the fact that carrier concentration decreases with time. Also the process of recombination takes place with respect to time which decreases the value of photocurrent. A state is obtained where the process of generation of charge carrier and recombination reaches to an equilibrium in constant illumination. This results in a constant photocurrent with respect to time. When light is turned off, photocurrent decreases abruptly and after a few seconds, it decreases steadily with respect to time. Here surface recombination is very high and it leads to a lower carrier concentration at the surface (Sze 2001). The system tends to its initial stage by relaxation process which gives low and steady decay of photocurrent. From figure 4 , it is also noted that the decay of photocurrent for the sintered film of chemically prepared $\mathrm{CdS}$ is fast and shows the high photosensitivity (ratio of $I_{\mathrm{p}} / I_{\mathrm{d}}$ ) which indicates that the resistance of the film decreases very fast.

\section{Conclusions}

The technique of chemically prepared sintered films of CdS is cost effective and convenient. Besides, these films 
are suitable for the fabrication of semiconducting devices such as solar cells, photo detectors, etc.

\section{Acknowledgements}

Financial support from DRDO, New Delhi, is gratefully acknowledged. Thanks are also due to Dr Kedar Singh, Mr Vibhav K Saraswat and Mr V Kishore for helpful discussions from time to time.

\section{References}

Britt J and Ferekids C 1993 Appl. Phys. Lett. 622851

Bogdanov S V and Lyssenko V G 1988 Phys. Status Solidi B150 593

Bouchenaki Ch, Ullrich B, Zielinger J P, Cong H N and Chartier P 1990 J. Cryst. Growth 101797

Chu T L, Chu S S, Britt J, Ferekids C, Wang C, Wu C Q and Ullal H S 1992 IEEE Electron. Dev. Lett. EDL-13 303

Cong H N and Chartier P 1993 Sol. Energy Mater. Solar Cells 30127

Das S K 1993 Solar Energy Mater. Sol. Cells 29277
Edamura T and Muto J 1993 Thin Solid Films 235198

Gurumurugan K, Mangalraj D, Narayandass Sa K and Balasubramaniam C 1994 Phys. Status Solidi (a)143 85

Iyechika Y, Wigner G, Jager D, Witt A and Klingshirn C 1988 SPIE Opt. Comput. $\mathbf{8 8} 103$

Kerk J de and Kelly E F 1964 Appl. Phys. Lett. 52

Kumar V, Sharma S K, Sharma T P and Singh V 1999 Opt. Mater. 12119

Lee J S and Im H B 1980 J. Mater. Sci. 4703

Nakayama N, Matsumoto H, Nakano A, Ikegami S, Uda H and Yamashita T 1980 Jpn. Appl. Phys. 4703

Ocampo M and Sebastian P J 1994 J. Compos. Phys. Status Solidi 43 K24

Sebastian P J and Hu H 1994 Adv. Mater. Opt. Electron. 4407

Sharma T P, Sharma S K and Singh V 1992 C.S.I.O. Commun. 1963

Sravani C, Reddy K T R and Reddy P J 1992 Semicond. Sci. Technol. 61036

Stefko V V 1991 Sov. J. Commun. Technol. Electron. 36

Sze S M 2001 Semiconductor devices 2nd ed., p. 65

Tauc J (ed.) 1974 Amorphous and liquid semiconductors (New York: Plenum) p. 159 